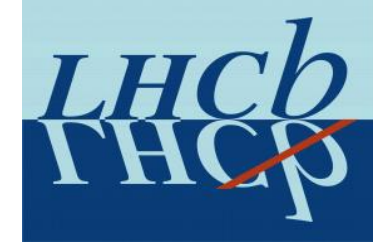

\title{
Radiation damage on the
}

\section{LHCb-VeLo}
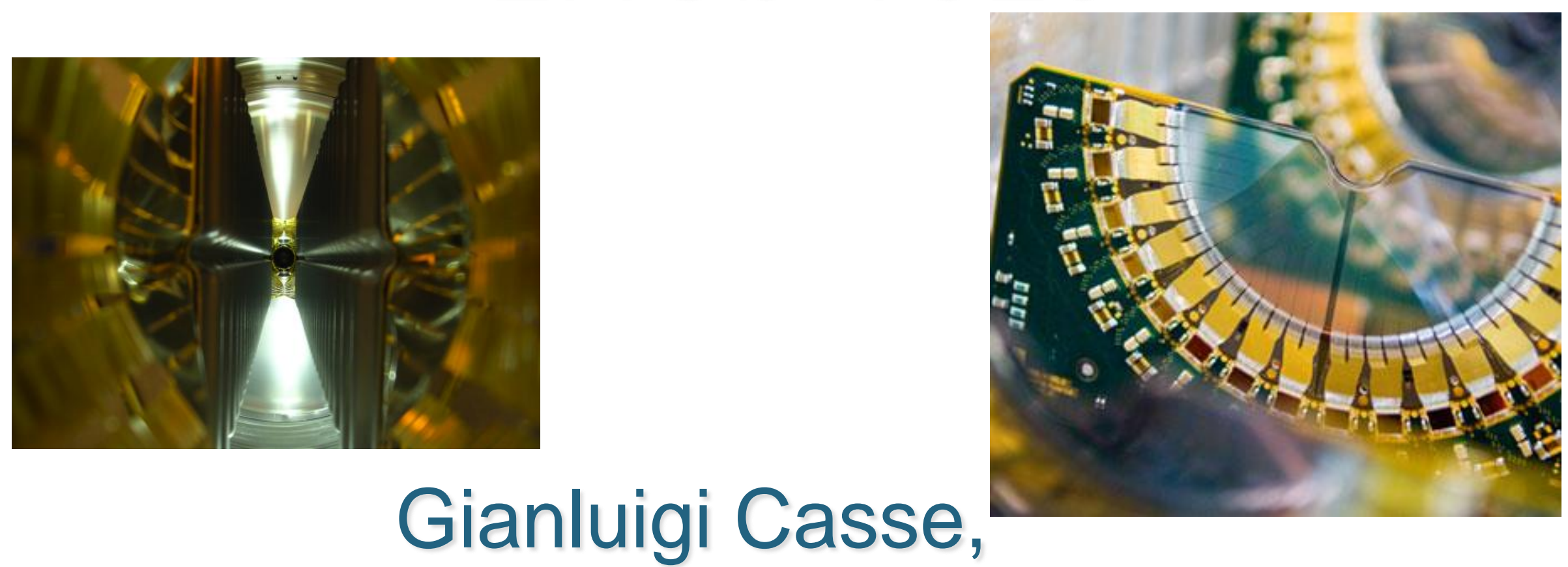

Gianluigi Casse,

on behalf of $\mathrm{LHCb}$ 


\section{The Detector}
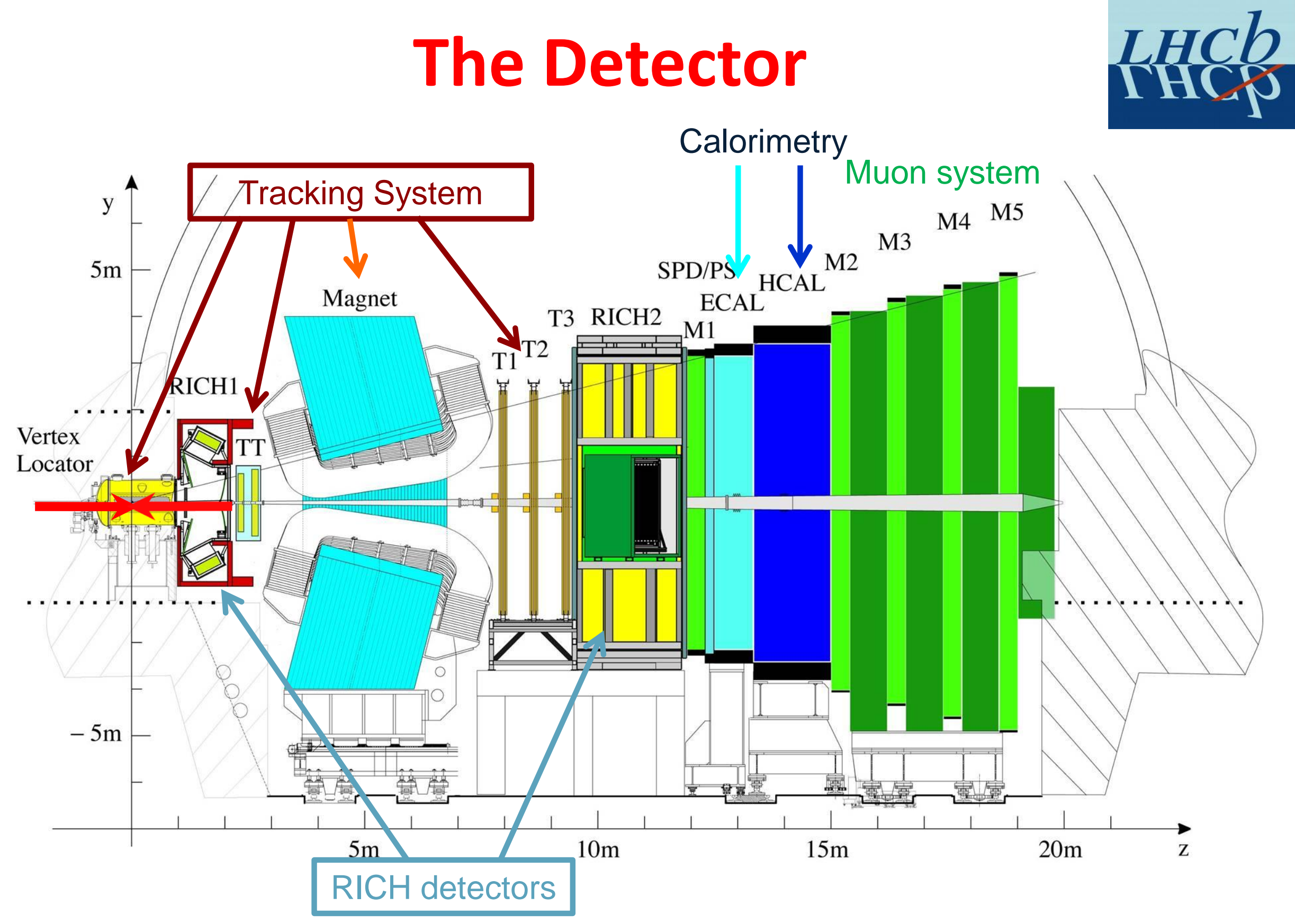


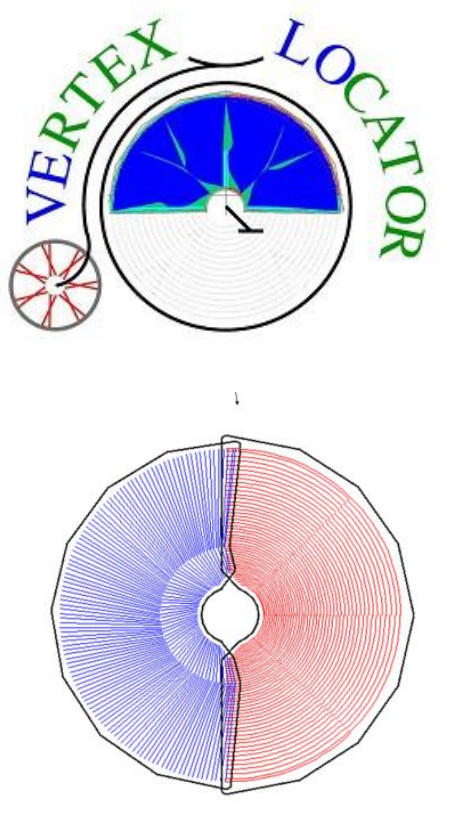

VELO fully closed (stable beam)

\section{The VELO}
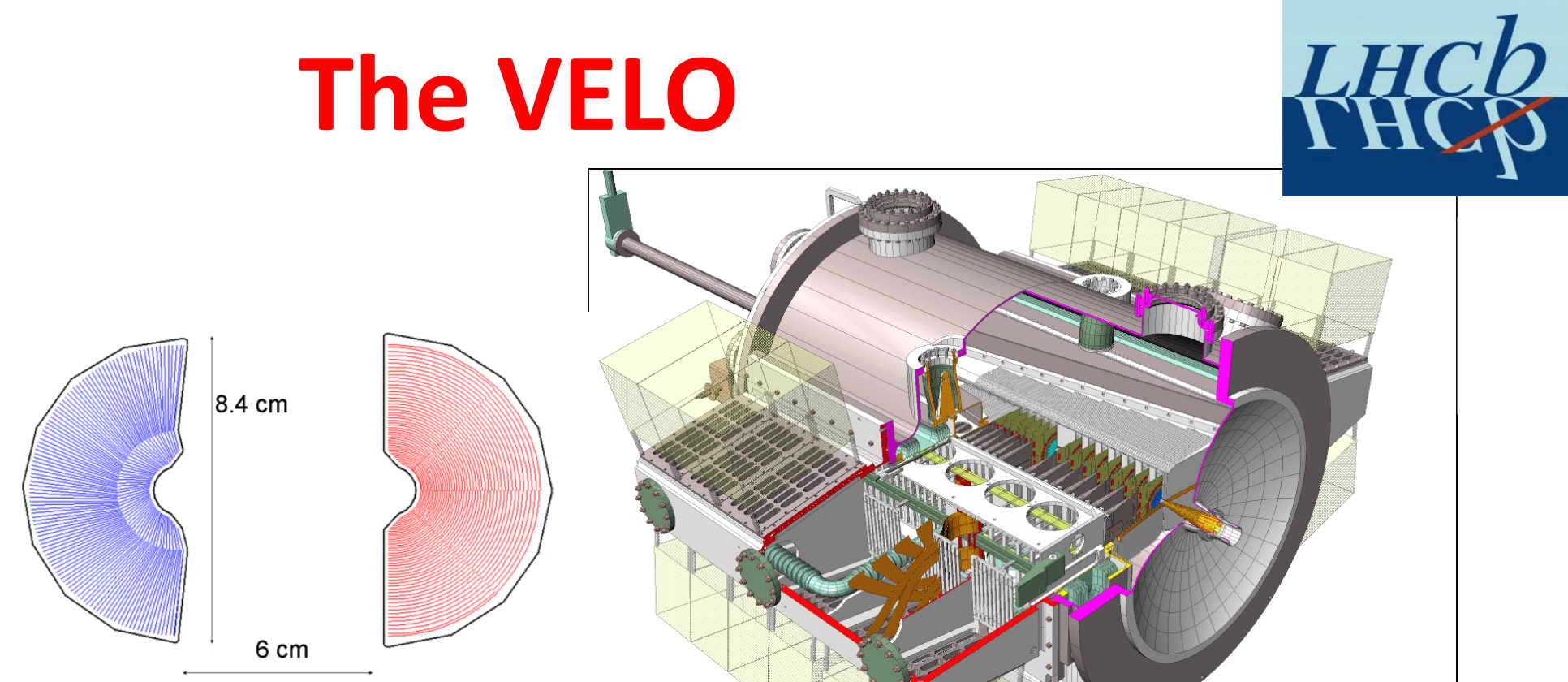

VELO fully open

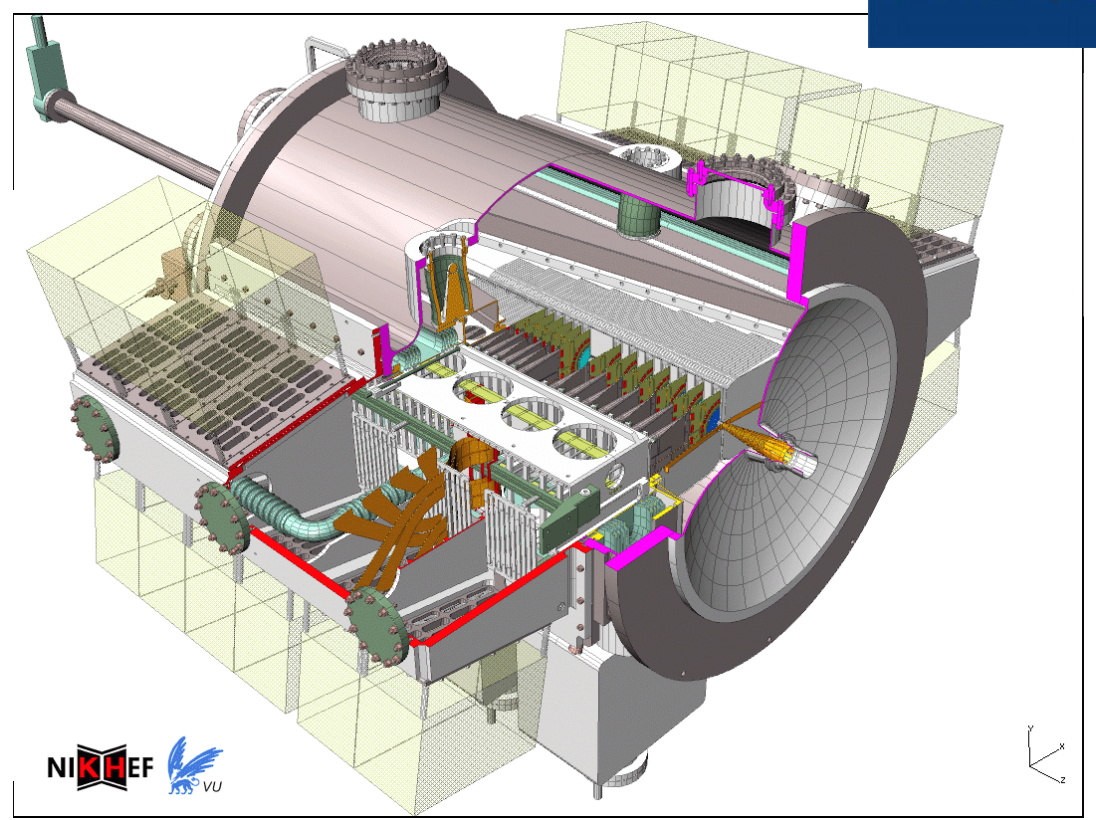

$\checkmark$ Retractable detector halves

$\checkmark 21$ R-Phi measuring modules per half

$\checkmark$ Close to beam-line $(8 \mathrm{~mm})$

$\checkmark$ Operates in secondary vacuum

$\checkmark$ A 300 $\mathrm{mm}$ thick Al foil separates from the beam vacuum

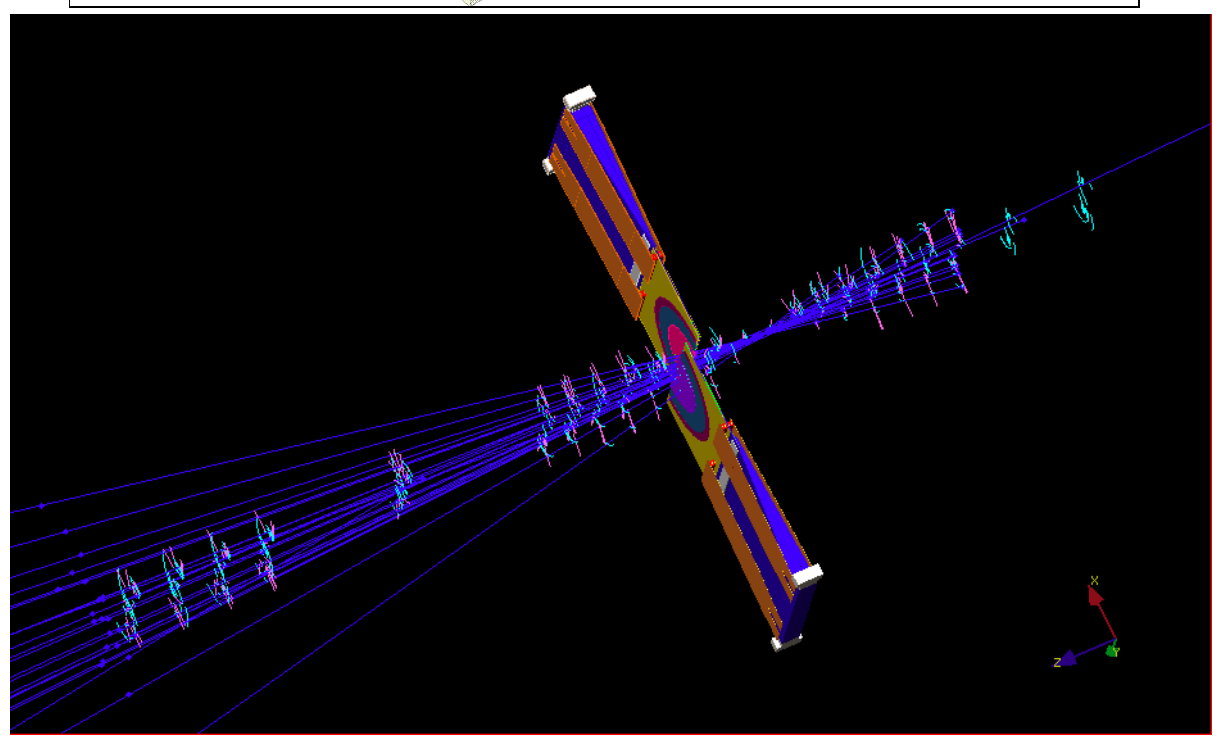




\section{VELO sensors}

Radiation hard design $\longrightarrow$ n-strip readout

$2^{\text {nd }}$ metal layer

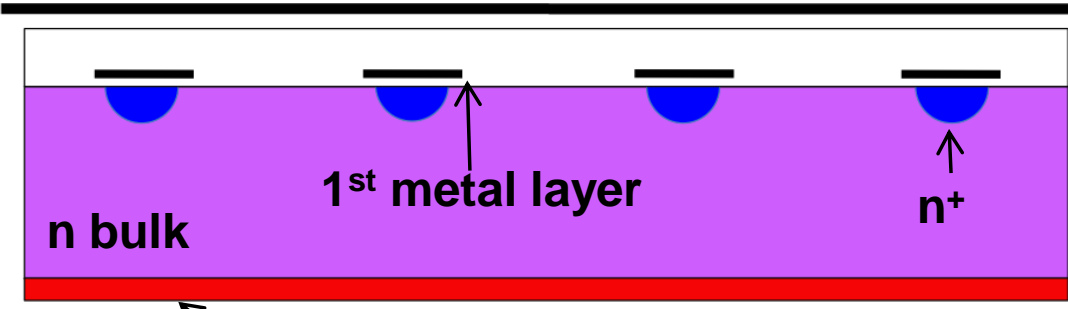

$p^{+}$implant

$2^{\text {nd }}$ metal layer

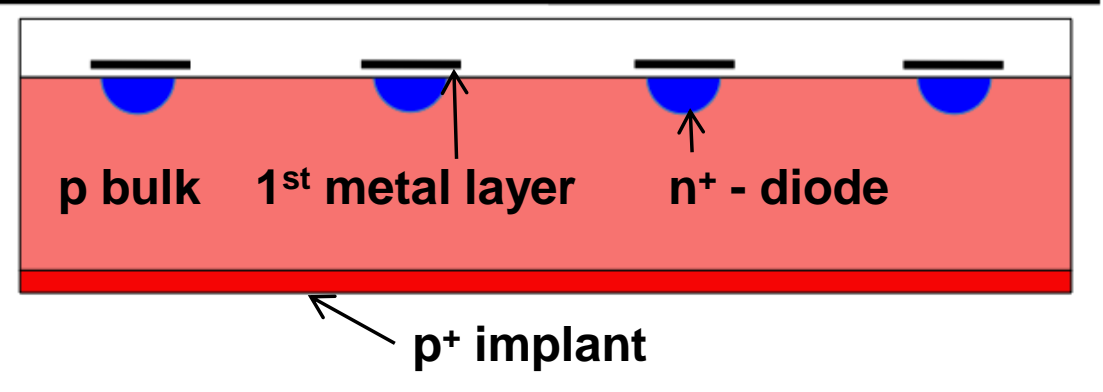

82 n-in-n sensors

Depletion region grows from the backplane junction. Conductivity type inversion after a few $10^{12} \mathrm{n}_{\text {eq }} \mathrm{cm}^{-2}$. Interstrip-isolation by $p$-spray.

\section{2 n-in-p sensors}

Depletion region grows from the strip implant. No type inversion. Interstrip-isolation by $p$-spray. 


\section{Evaluation of Radiation Damage}

\section{Methods:}

- Changes of Current vs Voltage (IV)

- Current vs Temperature (IT)

- Changes of the full depletion voltage

- Cluster Finding Efficiency 


\section{Reverse Bias Current}

Two contributions: bulk and surface current Influence of surface current negligible after irradiation

\section{Bulk dominated before \\ Bulk dominated after}

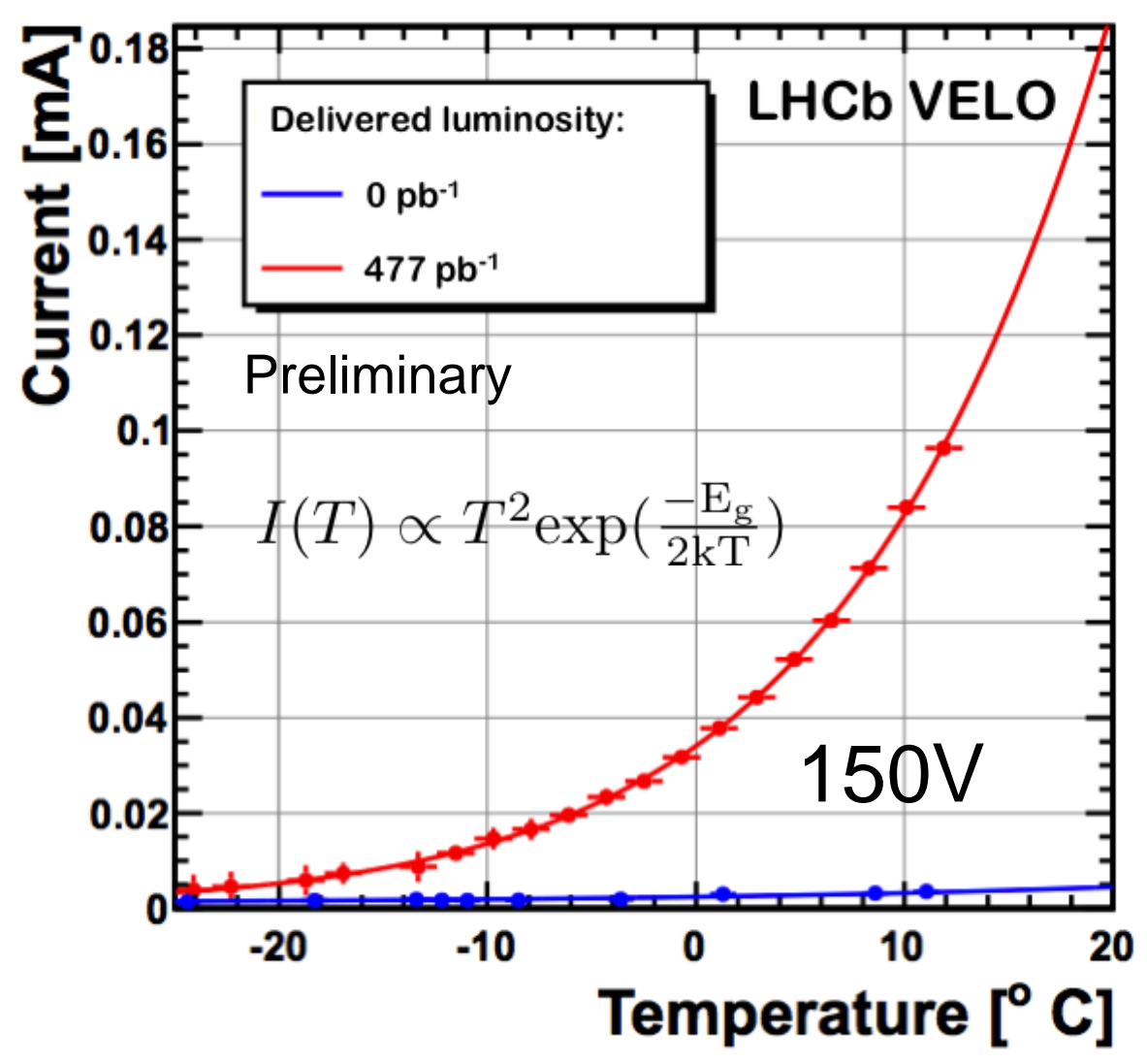

Surface dominated before Bulk dominated after

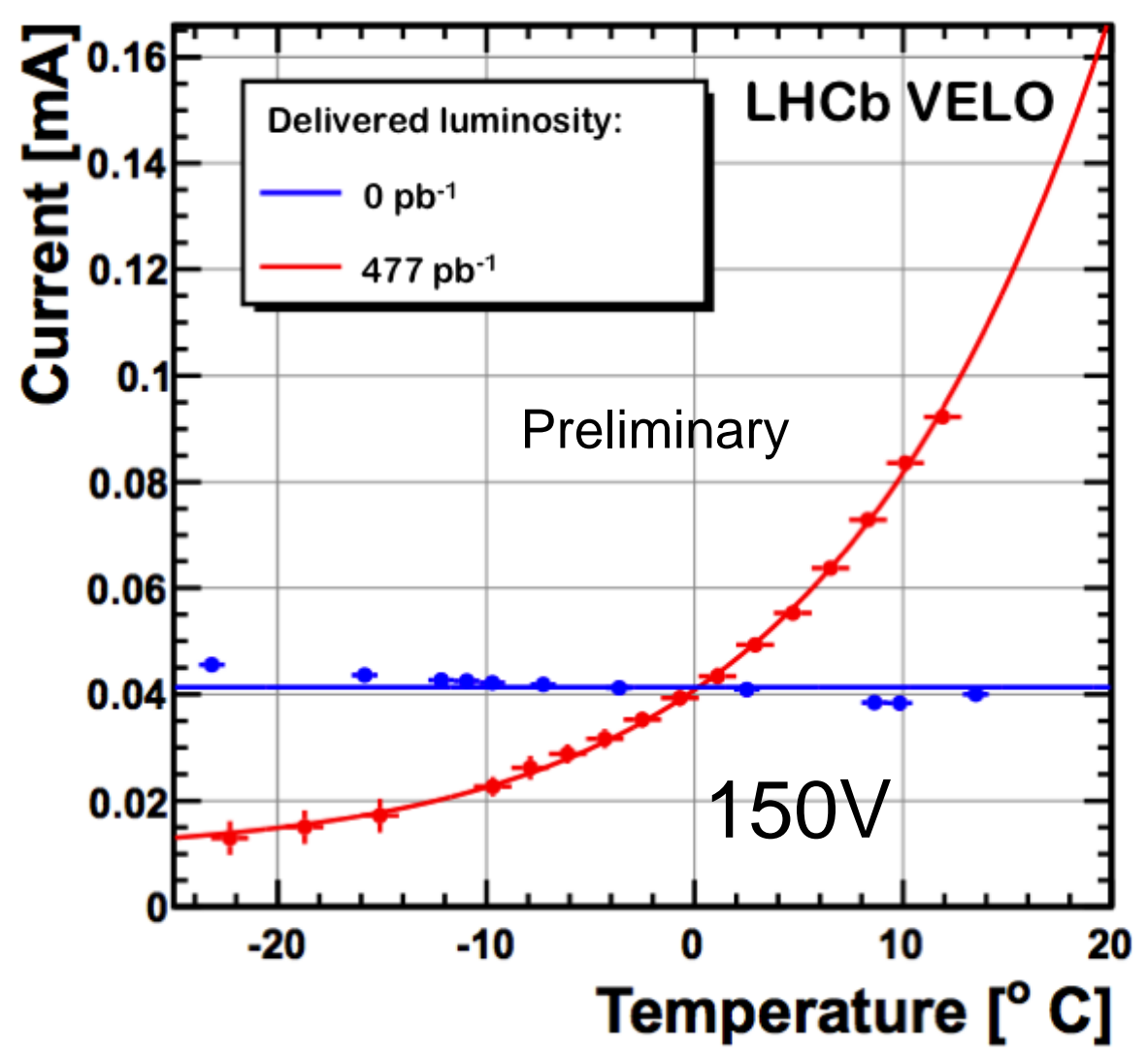




\section{Comparison with predicted fluence}

\section{$L H C b$ THAP}

Bulk current show an increase with fluence in line with delivered luminosity.

Trend of all sensors at $150 \mathrm{~V}$ and $-8^{\circ} \mathrm{C}$ :

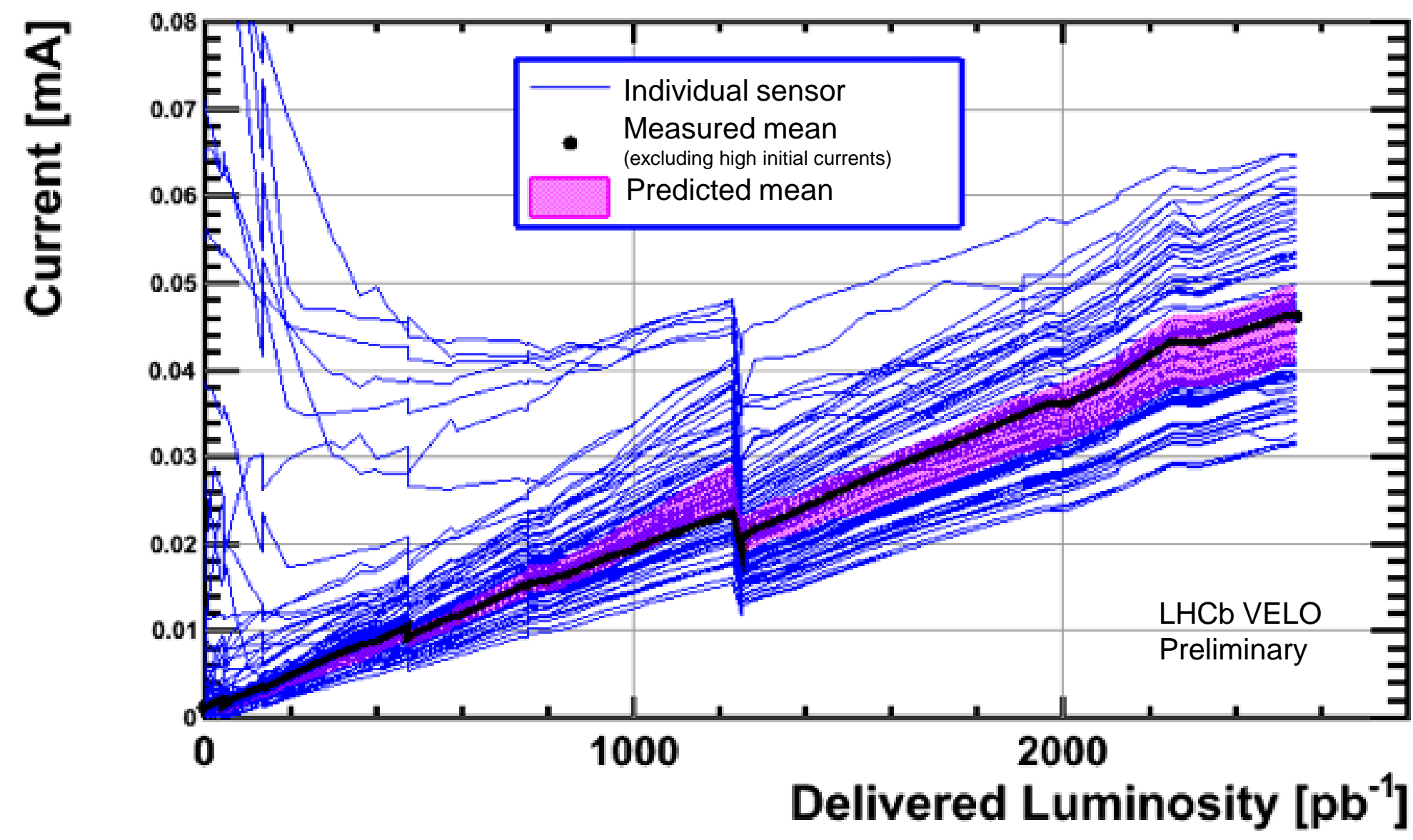

$\sim 1.9 \mu \mathrm{A}$ per $100 \mathrm{pb}^{-1}$ at $8^{\circ} \mathrm{C}$ 
$>$ Accurate measurement of the effective bandgap energy:

Bulk/Bulk current dominated before/after

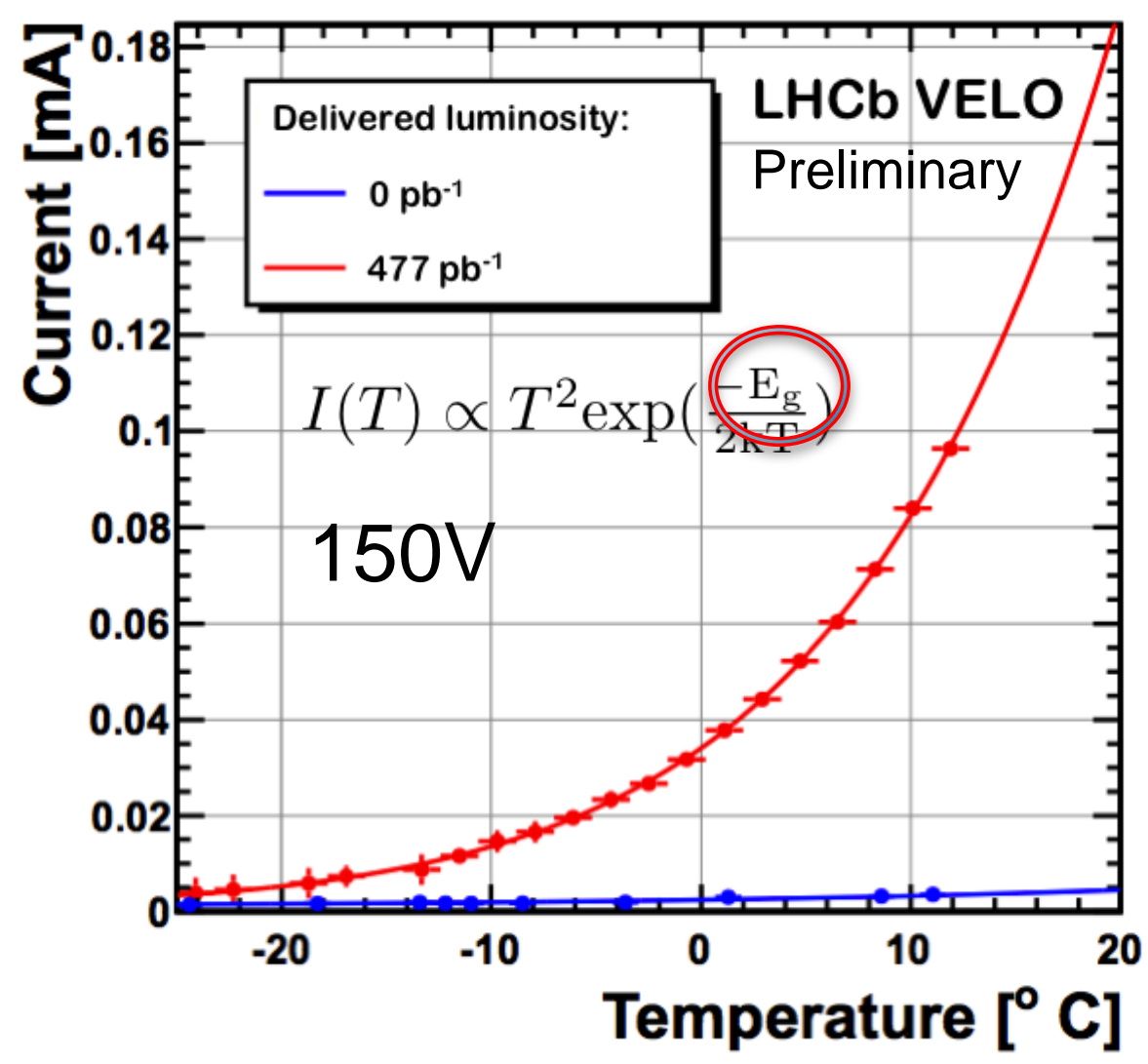

\begin{tabular}{ll}
\hline Preliminary & $\begin{array}{l}\text { "effective } \\
\text { band gap } \mathrm{E}_{\mathrm{g}} \text { " }\end{array}$ \\
\hline $\begin{array}{l}100 \mathrm{~V} \\
480 \mathrm{pb}^{-1}\end{array}$ & $1.12+-0.06 \mathrm{eV}$ \\
$150 \mathrm{~V}$ & $1.11+-0.07 \mathrm{eV}$ \\
$480 \mathrm{pb}^{-1}$ & \\
$150 \mathrm{~V}$ & $1.10+-0.04 \mathrm{eV}$ \\
$821 \mathrm{pb}^{-1}$ & \\
$150 \mathrm{~V}$ & $1.14+-0.04 \mathrm{eV}$ \\
$1204 \mathrm{pb}^{-1}$ & \\
\hline \hline Literature: $\mathrm{Eg}=1.21 \mathrm{eV}$ \\
\hline
\end{tabular}




\section{Changes of full depletion voltage}

For $\mathrm{n}^{+}$-on- $\mathrm{n}$ sensors we expect typeinversion

For $n^{+-o n-p}$ we expect initial decrease of $V_{F D}$ followed by linear increase

Standard measurement method uses C-V scans only possible before irradiation

After installation $\mathrm{V}_{\mathrm{FD}}$ depends on radius, so we need to use an alternative method.
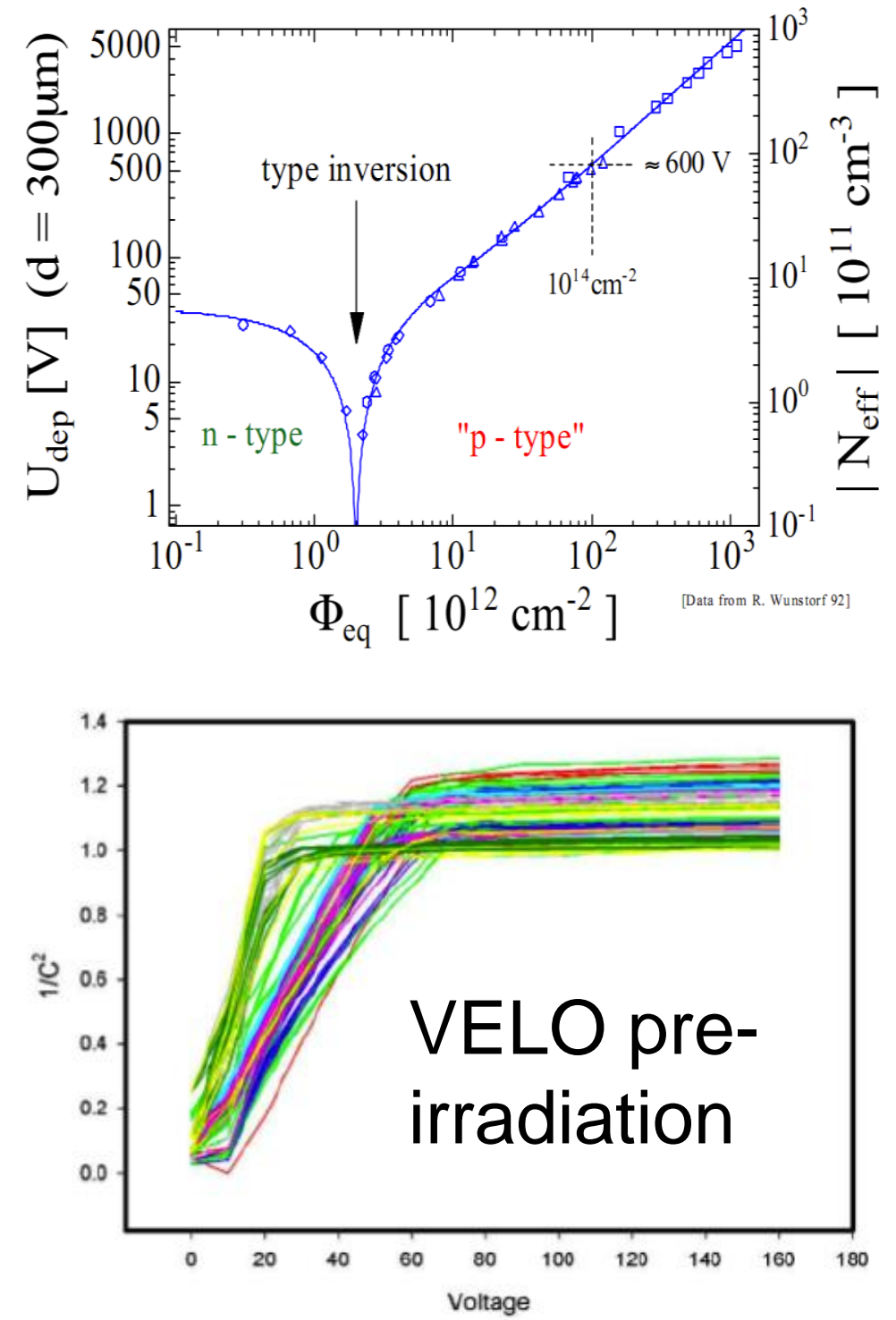


\section{Charge collection efficiency method}

Using reconstructed unbiased tracks:

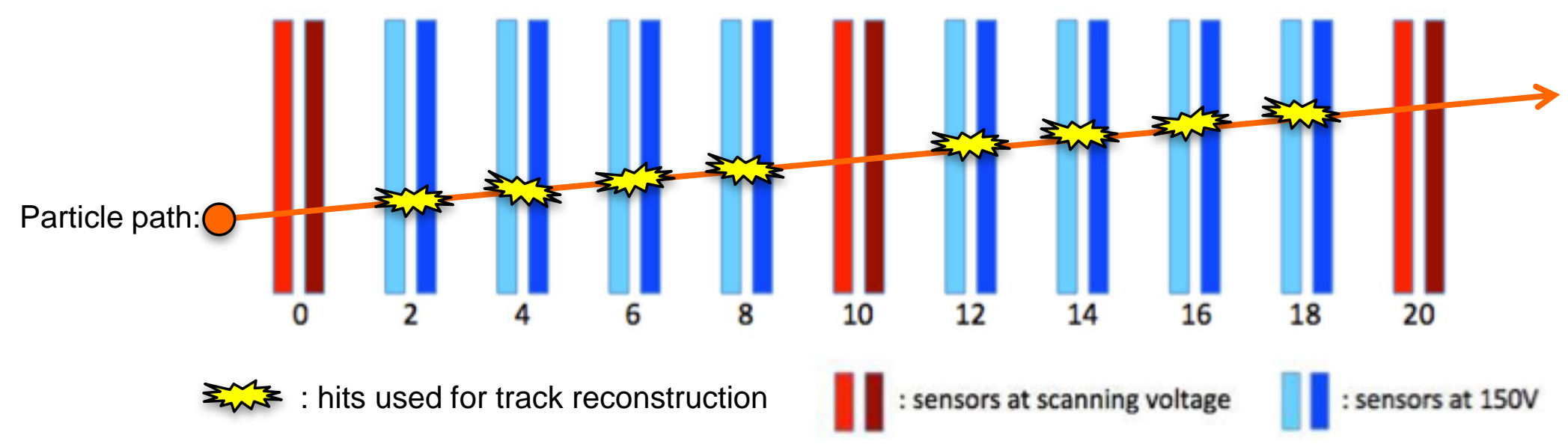

Extrapolate the track to a strip on the test sensor and record amount of charge in this area.

Vary the voltage of the test sensors between 0 and 150V. 


\section{CCE method}

Collect data for each sensor at various bias voltages
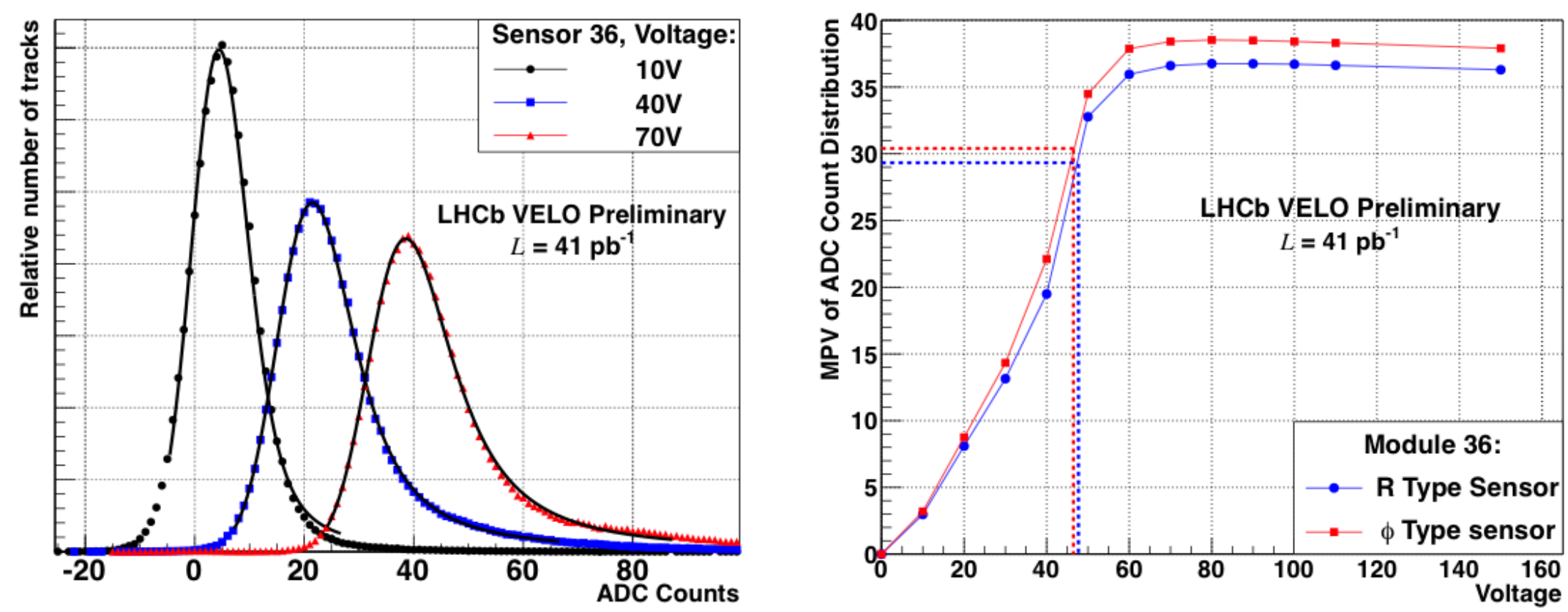

Fit the MPV of the distribution and plot vs bias voltage.

Define the full depletion voltage $\left(\mathrm{V}_{\mathrm{FD}}\right)$ as the voltage at which the MPV is $80 \%$ of maximum.

This method is still accurate after the fluences currently accumulated. 


\section{$V_{F D}$ vs fluences}

$V_{F D}$ at different sensor (n-in-n) radii after various fluences:

- Decrease of $\mathrm{V}_{\mathrm{FD}}$ with luminosity

- Type-inverted in low radius regions

- $\operatorname{Min} \mathrm{V}_{\mathrm{FD}} \sim 20 \mathrm{~V}$

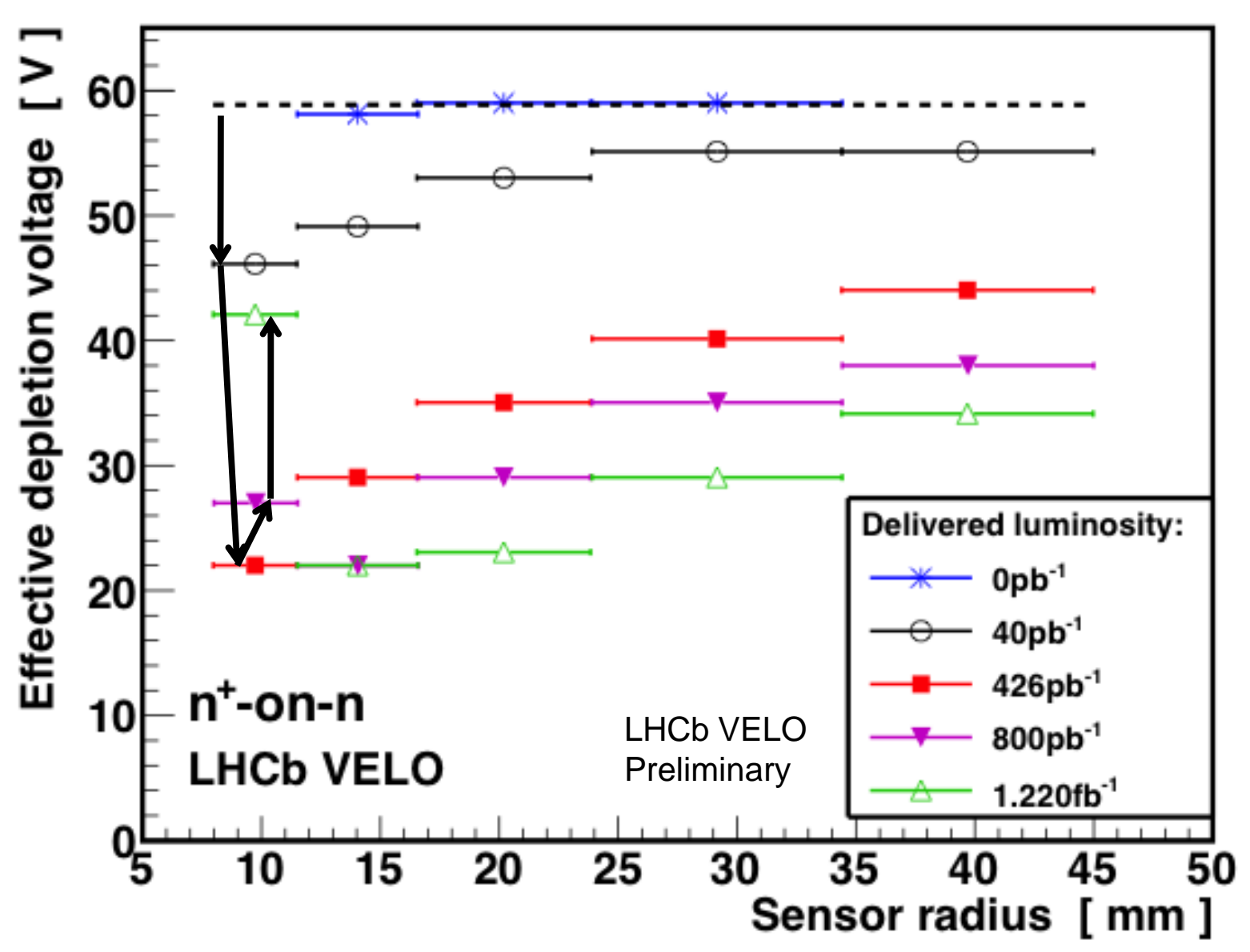




\section{$V_{F D}$ vs fluence}

$V_{F D}$ at different sensor ( $\left.n-i n-p\right)$ radii after various fluences:

- Decrease of $\mathrm{V}_{\mathrm{FD}}$ with luminosity

- Type-inverted in low radius regions

- Initial shallow acceptor (B) removal reduces $V_{F D}$

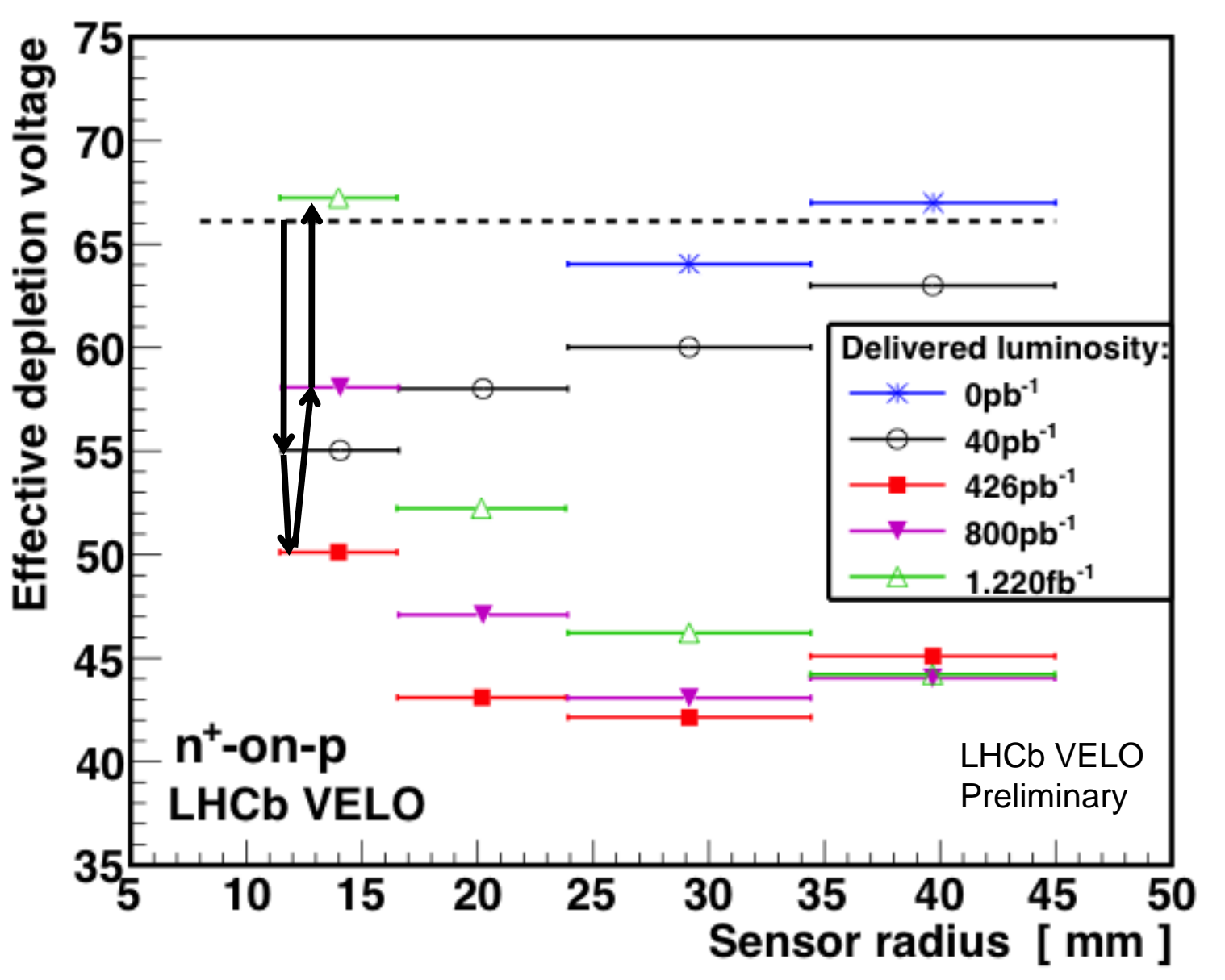




\section{For all VELO sensors:}

\section{vs fluence}

\section{$L H C b$
$M A P$}

1. $V_{F D}$ decreases with fluence to a minimum of $\sim 18 \mathrm{~V}$ (n-type bulk sensors).

2. Inversion point is $\sim 10-15 \times 10^{12} \mathrm{n}_{\text {eq }}$

3. After type-inversion, $\mathrm{n}^{+}$-on- $\mathrm{n}$ increase at a similar rate to $n^{+}-0 n-p$.

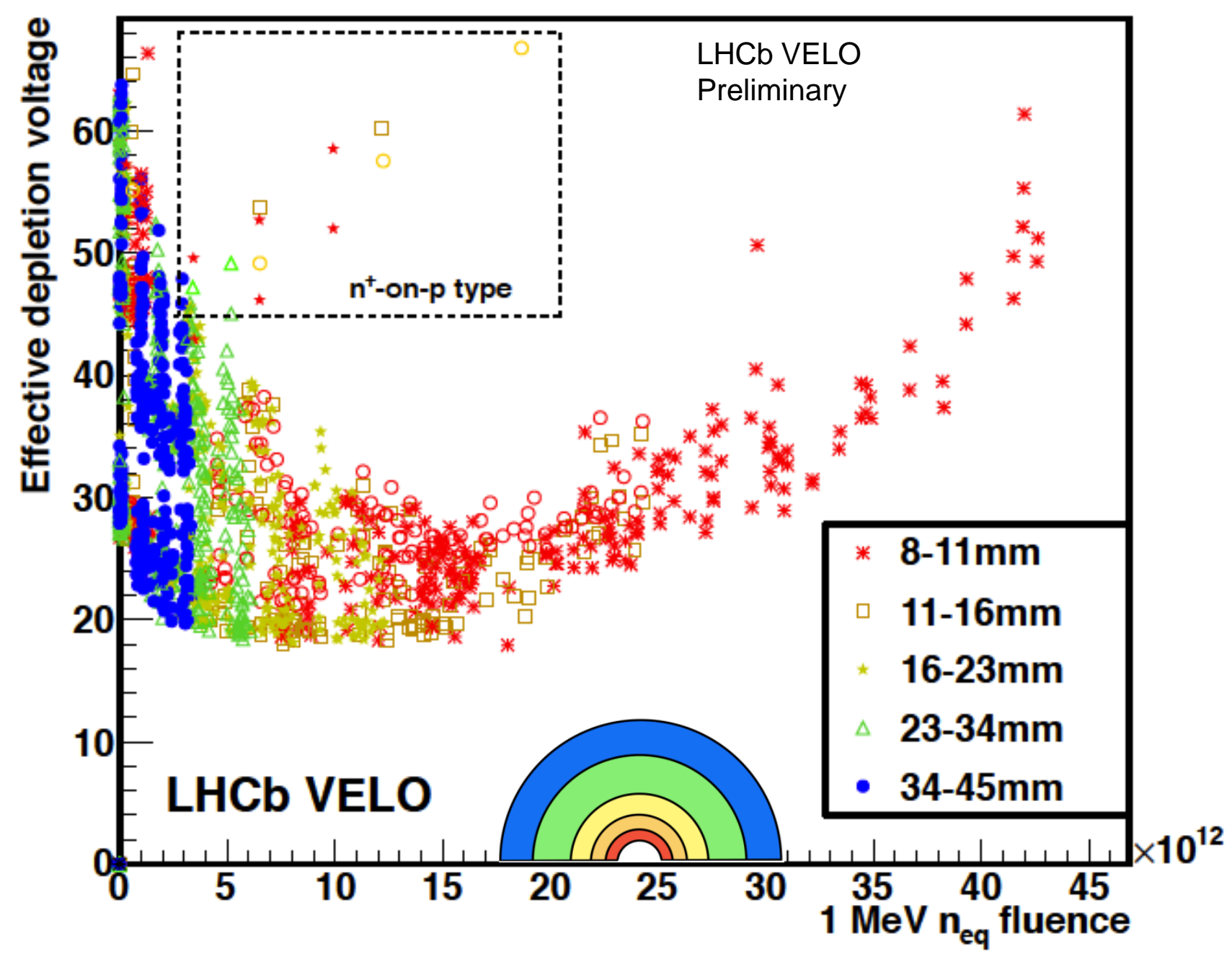




\section{$V_{F D}$ vs fluence}

\section{IHCh}

Comparison with Hamburg parameterisation:
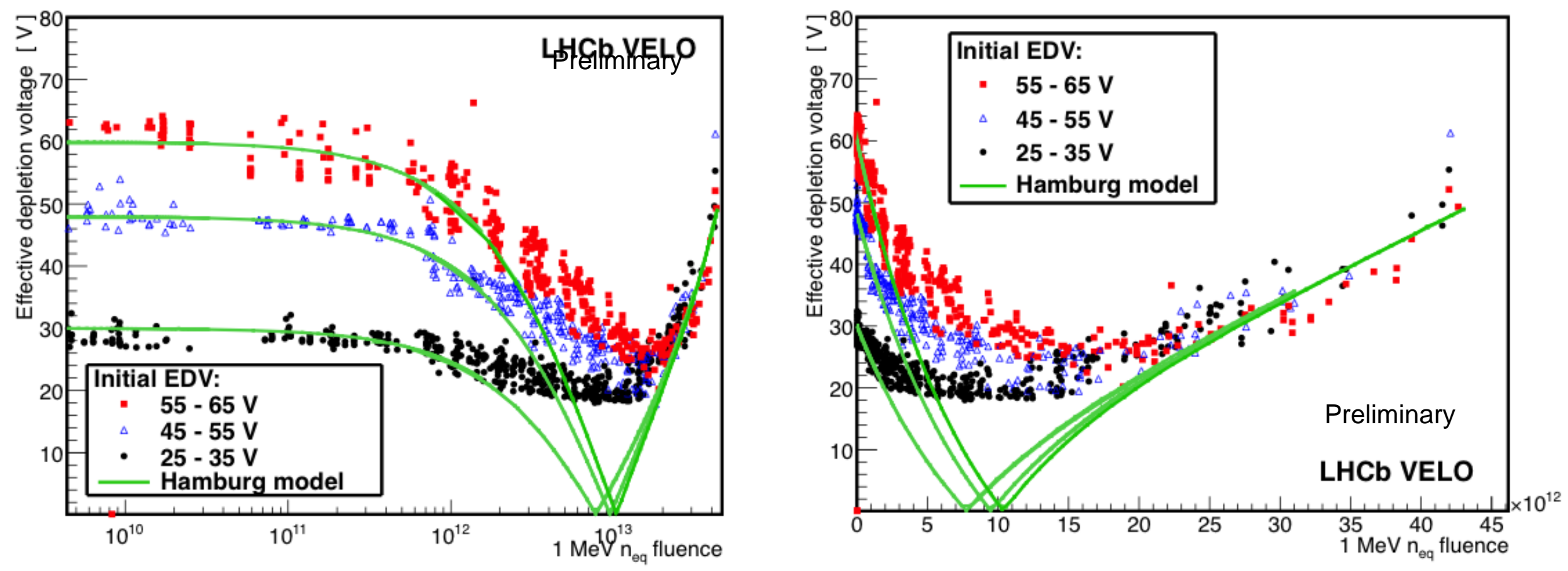

Good agreement a part from around type-inversion. The CCE method needs sufficient electric field for efficient charge collection. 


\section{$\mathrm{CC}(\mathrm{V})$ of $\mathbf{n}$ and $\mathbf{p}$-type sensors}

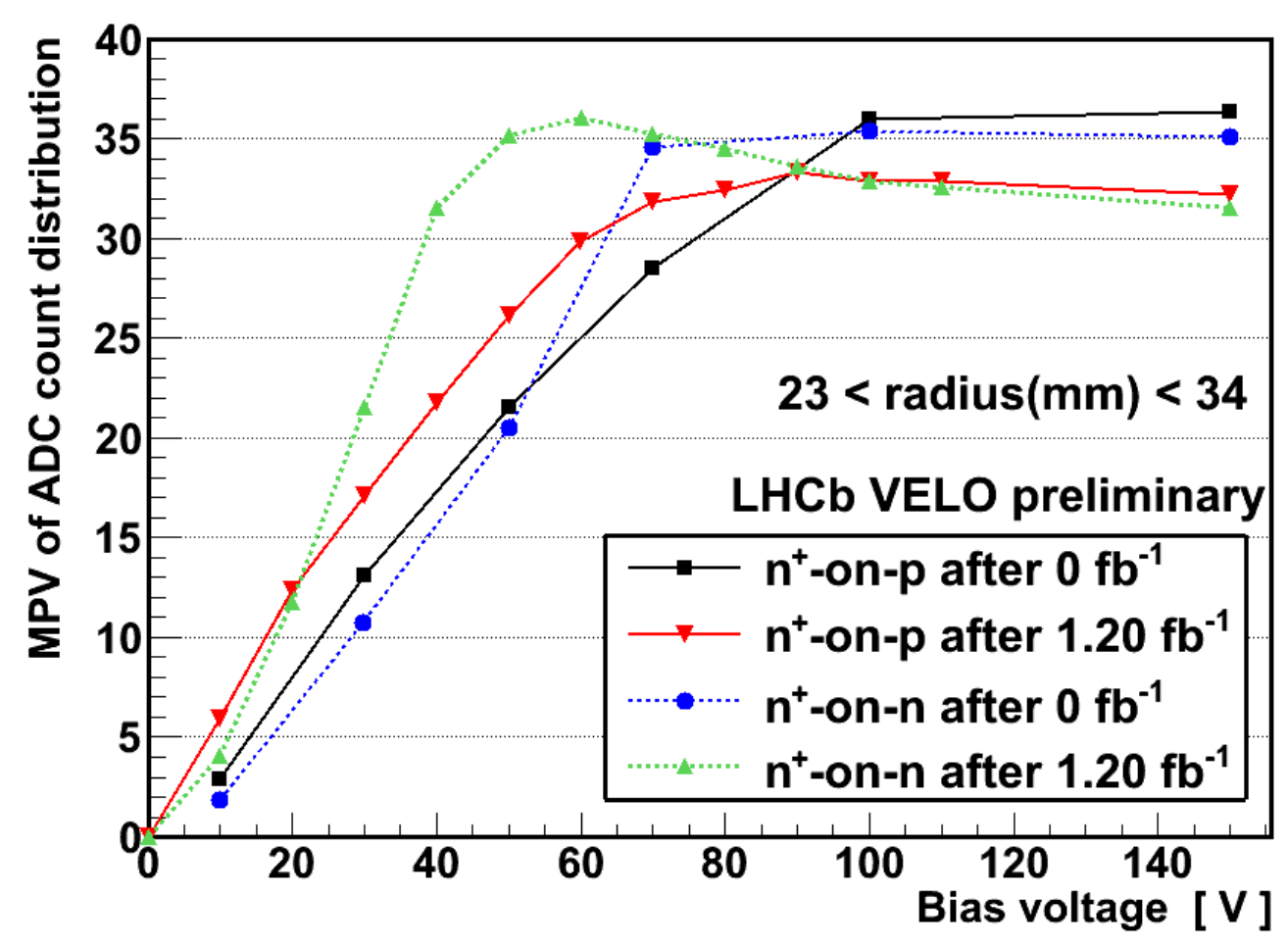

The MPV vs voltage for the outer region of $n-o n-n$ and an $n-o n-p$ sensors. 


\section{Cluster Finding Efficiency (CFE)}

\section{.... and more irradiation..}

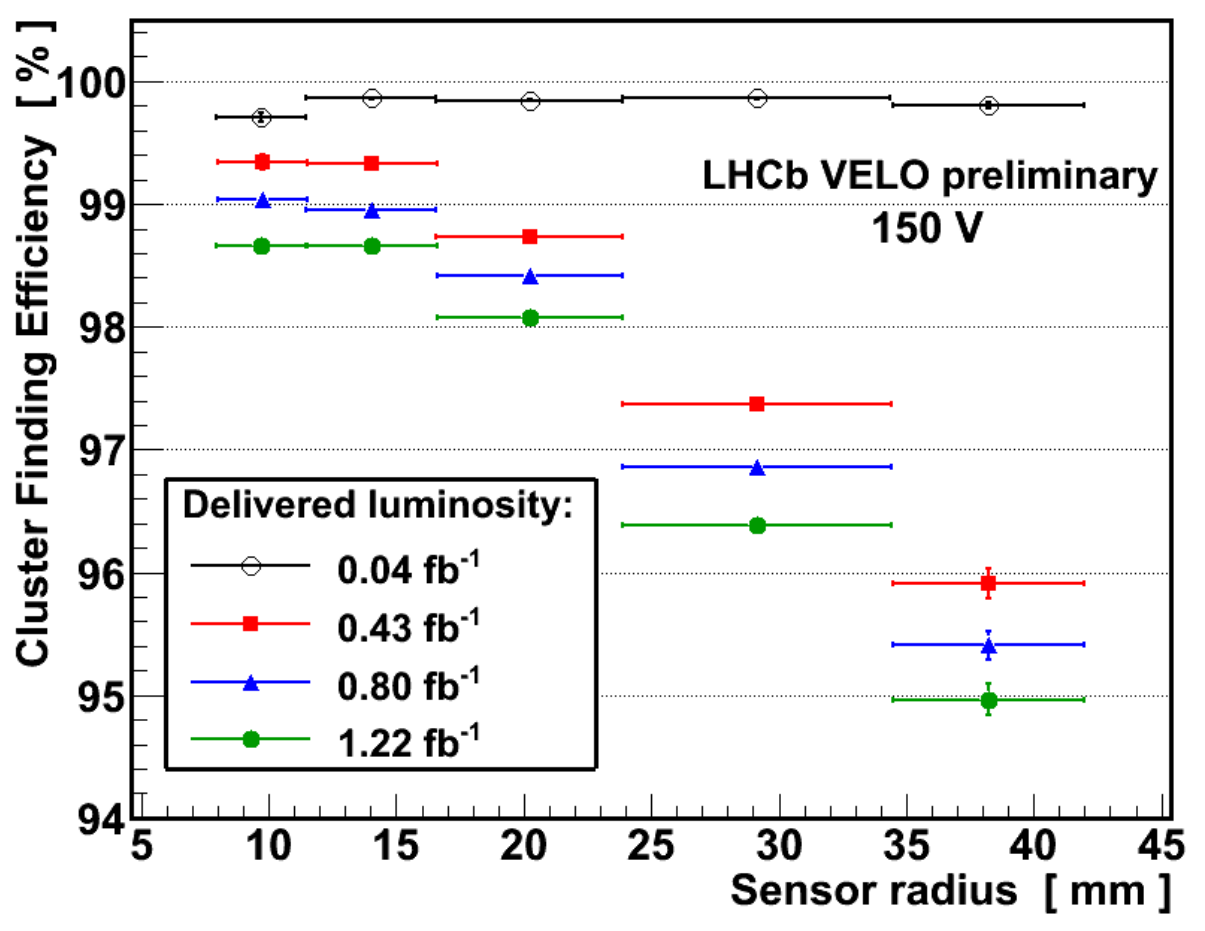

CFE for R-sensor 34 as a function of radius after various delivered luminosities.

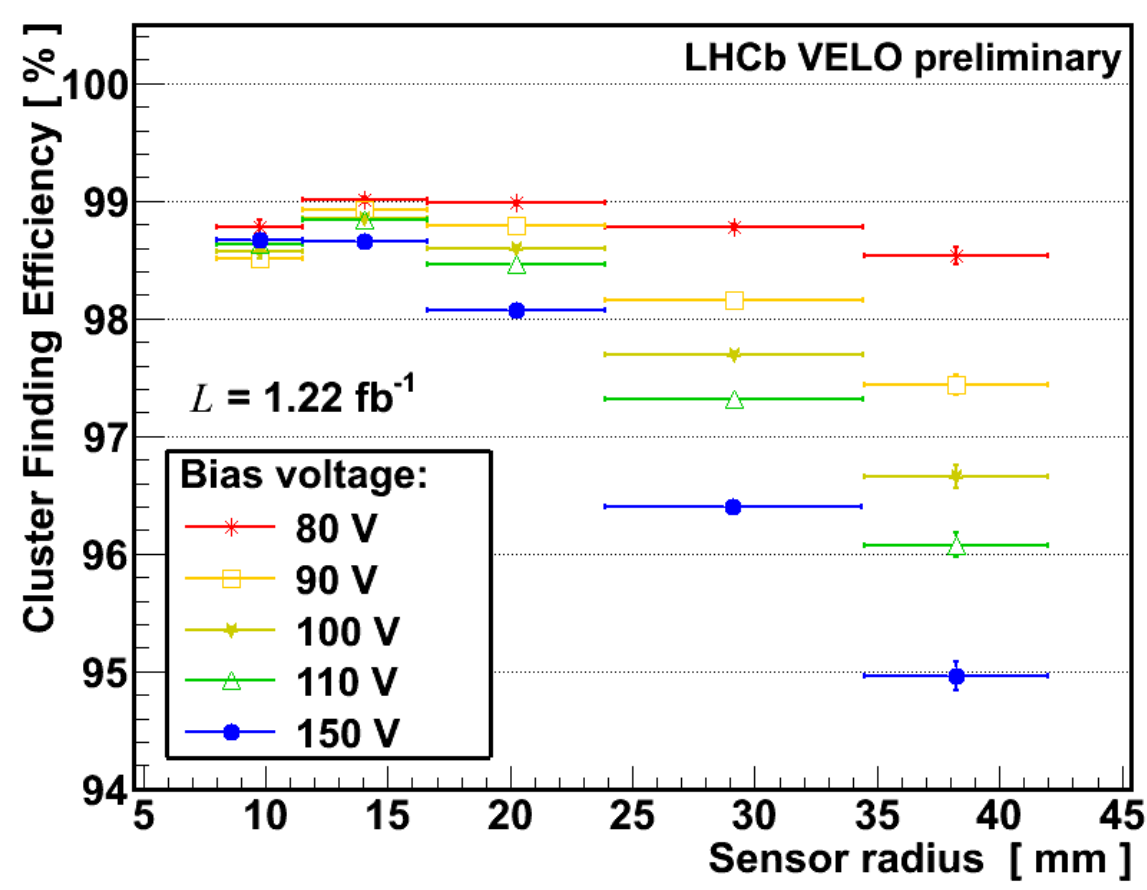

CFE for R-sensor 34 as a function of radius at different bias voltages. 


\section{Routing via $2^{\text {nd }}$ metal layer}

$1^{\text {st }}$ metal layer $\mathrm{AC}$ coupled to the strips.

$2^{\text {nd }}$ metal layer to connect inner strips to read-out electronics.

For R-sensors, the routing lines are perpendicular to strips:

\section{small $\mathrm{R}$}

RL width 11um

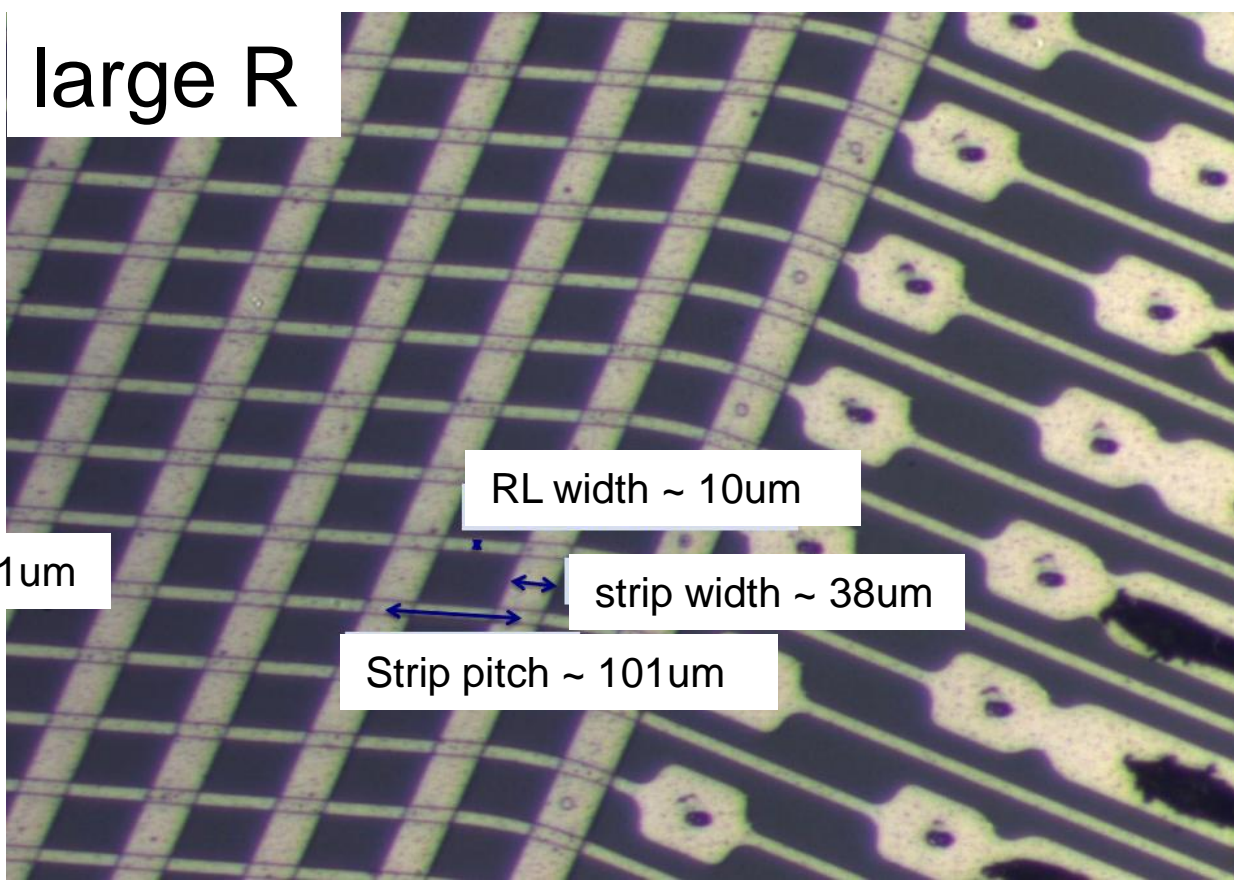

Phi-sensor routing lines to the inner section are above outer strips (screening).

$3.8 \pm 0.3 \mu \mathrm{m} \mathrm{SiO}_{2}$ insulation between metal layers. 


\section{Routing via $2^{\text {nd }}$ metal layer}

The second metal layer routing lines in R-sensors:

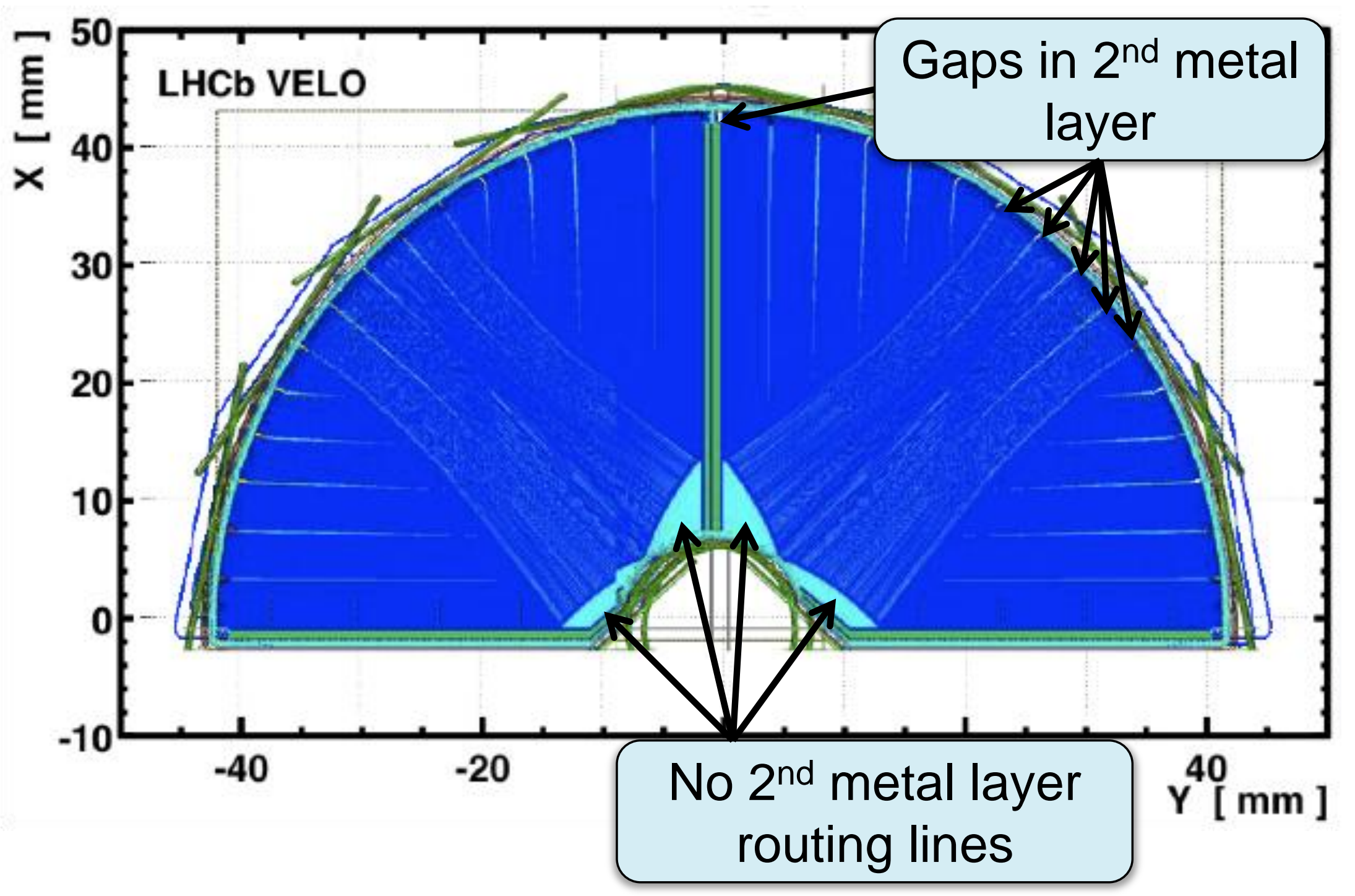




\section{CFE}

\section{Cluster finding efficiency in R-sensors:}

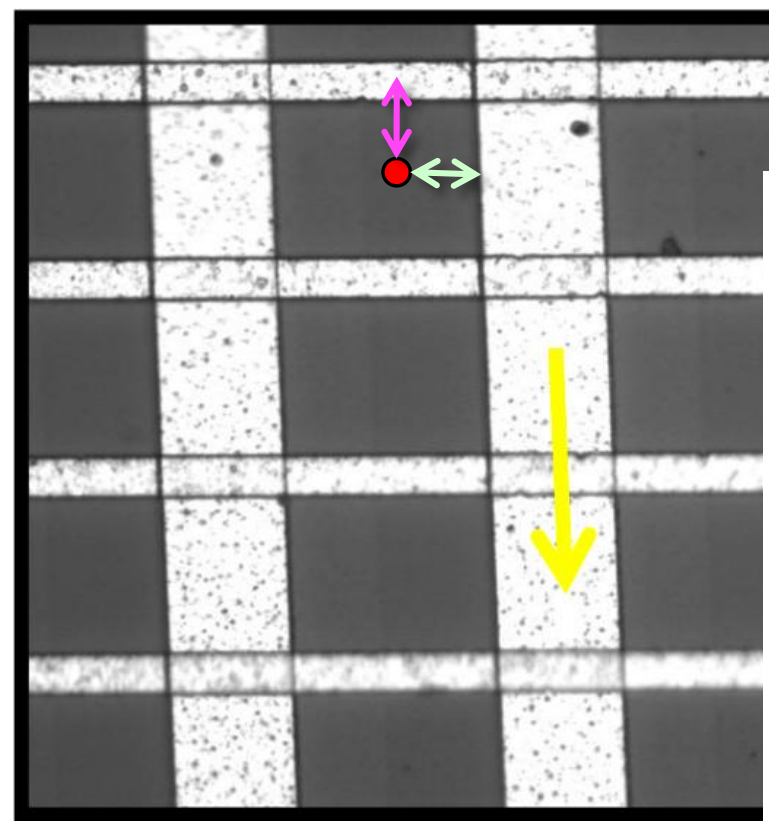

$\mathrm{RL}$ dist $=$ distance to nearest routing line

$\mathrm{d}=$ distance to nearest strip edge

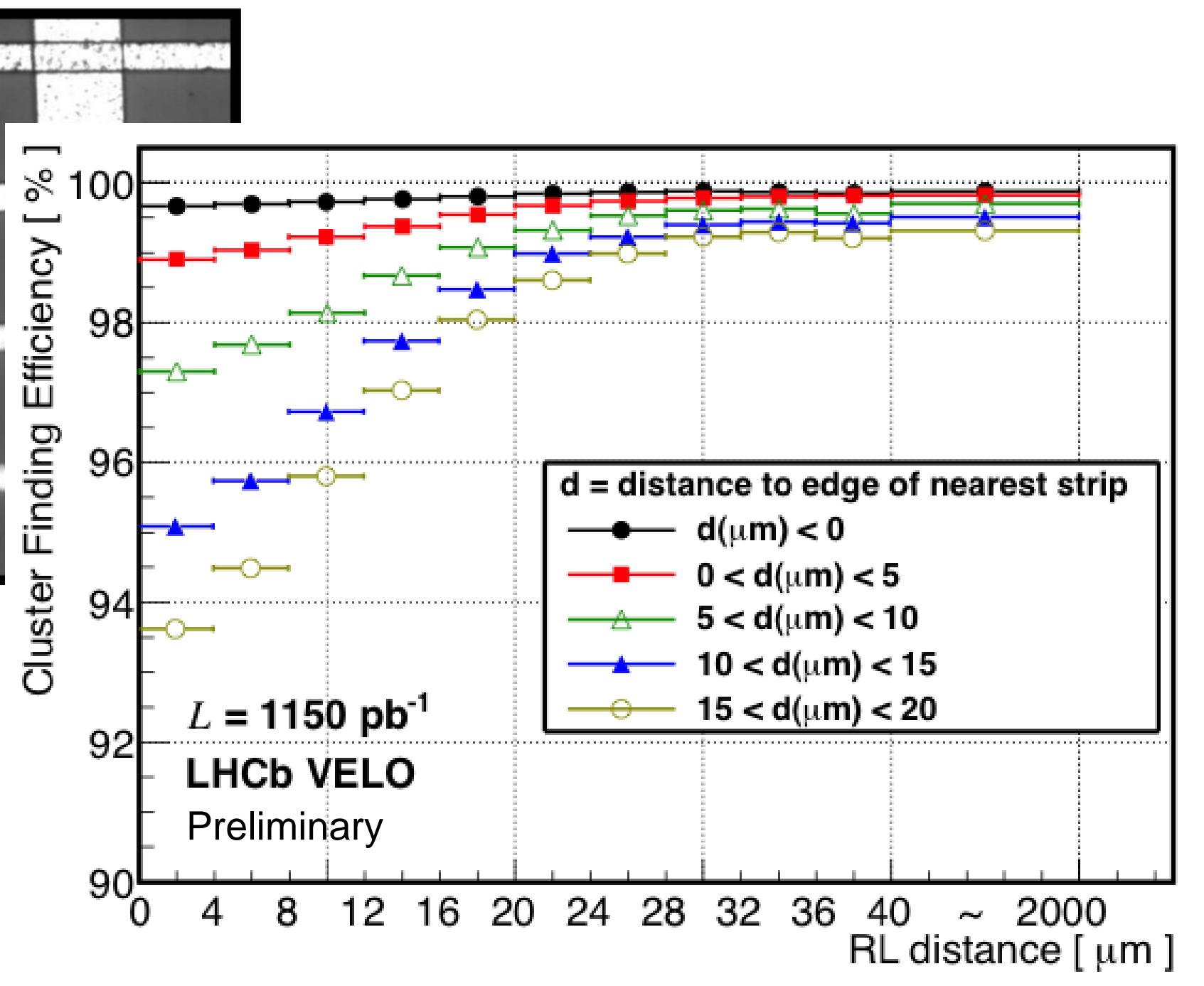




\section{SUMMARY}

- Variety of analysis techniques give us excellent understanding of the health of our detectors. The MC estimate of the received fluence with radius and $z$ agrees with changes of the electricsal performances of the sensors, giving confidence that the monitoring is well in hand.

- Second metal layer CFE decrease is as much at $~ 10 \%$ in worst effected regions. But there has been no significant decrease in tracking efficiencies (within $0.3 \%$ errors).

- "Annealing" for recovering both CCE and current is a weapon still saved for later days.

- Note: last week LHCb has passed the $1.5 \mathrm{fb}^{-1}$ threshold!! 